\title{
O ENSINO DA GEOGRAFIA NO ENSINO
}

\author{
Ledalene da Conceição Gonçalves Menezes ${ }^{1}$
}

Verilane dos Santos Menezes ${ }^{2}$

\section{Resumo}

Este trabalho aborda uma discussão sobre o ensino de Geografia para o Ensino Médio com o uso das mídias digitais em sala de aula para envolver o discente no processo de ensino aprendizagem e promover ao aluno aulas mais dinâmicas que ajude a aprender melhor o conteúdo e refletir sobre os problemas apresentados. Nesta pesquisa foi adotada a metodologia da pesquisa bibliográfica. Conclui-se que o uso de várias ferramentas tecnológicas nas aulas de geografia promove uma melhor interação no âmbito escolar. Desta forma pode-se tornar as aulas mais dinâmicas proporcionando condições cada vez mais adequadas para que docentes e discentes tirem proveito da utilização das tecnologias digitais em benefício do ensino e da aprendizagem.

Palavras-chave: Ensino. Geografia Tecnologias Digitais.

\section{Abstract}

This work addresses a discussion about teaching Geography for High School with the use of digital media in the classroom to involve the student in the teaching-learning process and to promote the student more dynamic classes that help to better learn the content and reflect on the problems presented. In this research, the methodology of bibliographic research was adopted. It is concluded that the use of various technological tools in geography classes promotes better interaction in the school environment. In this way, classes can be made more dynamic, providing increasingly adequate conditions for teachers and students to take advantage of the use of digital technologies for the benefit of teaching and learning.

Keywords: Teaching. Geography Digital Technologies.

\section{Introdução}

Neste artigo serão abordadas questões sobre ensinar e aprender geografia: para além dos PCN (1998) no ensino médio preocupando-se com os conhecimentos científicos, e sua respectiva abordagem; a relação dialógica

\footnotetext{
${ }^{1}$ Mestra em Ciências da Educação pela FICS; Especialista em Educação Ambiental pela FAAC. Especialista em Pisicopedagogia Institucional e Clínica pela FACCEBA. Licenciada em Geografia pela UNIJORGE. Docente na Escola da Polícia Militar Francisco Pedro de Oliveira em Candeias/Ba. E-mail le.goncalves@yahoo.com.br

2 Mestra em Ciências da Educação pela FICS; Especialista em Metodologia do Ensino, Pesquisa e Extensão em Educação pela Uneb. Licenciada em Pedagogia pela Uneb, Licenciada em Geografia pela Face. Docente na Escola Papa Paulo VI em Candeias/Ba e na Escola Januário Ribeiro em São Sebastião do Passé/Ba. Email verys2_lane@hotmail.com
} 
no ensino da geografia; as mídias no cotidiano dos docentes do ensino médio; e a formação continuada das TICs para os professores de geografia construindo como ideia principal pensar e transformar o mundo que nos rodeias tendo como pressuposto conhecer ao aportes científicos, tecnológicos, assim como a realidade política.

Nos dias atuais existe uma necessidade de preparar o aluno para o dia de amanhã, fazer dele um cidadão pronto para enfrentar com autonomia e poder de decisão as mais diversas situações. É nesse sentido que viso utilizar abordagens que são dadas ás questões ambientais, econômicas e culturais em produções cinematográficas que atingem o público de maneira geral. Tais produções contribuíram para a formação de opiniões sobre as problemáticas trabalhadas. Pois diversos conteúdos de Geografia podem ser debatidos através de filmes, proporcionando condições para uma reflexão crítica dos acontecimentos. Para o PCN de Geografia pode-se afirmar que:

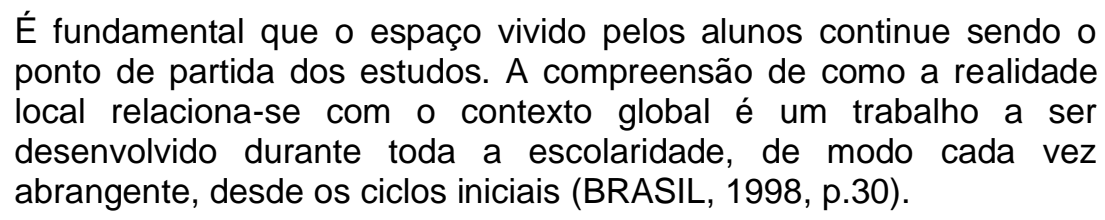

Dependendo da maneira como é ensinado, se fará presente na realidade de nossos alunos, ampliando seu conhecimento e novas perspectivas de leitura de mundo.

\section{Ensinar e Aprender Geografia: Para Além dos PCNs no Ensino Médio}

O Parâmetro Curricular Nacional (PCN) de geografia para o ensino sugerem que o ensino dessa disciplina contemple conteúdos de diferentes dimensões: conceituais que são atreladas aos fatos, conceitos e princípios; procedimentais estão ligadas as técnicas e métodos e os atitudinais a valores, atitudes e normas. Nesse sentido o conhecimento presente na composição cognitiva do sujeito podem possuir natureza conceitual, procedimental, e atitudinal. Aparentemente essa classificação e simples, no entanto carrega grande força pedagógica, pois diferencia os conhecimentos em conteúdo de aprendizagem, segundo o uso deles se deve fazer.

Percebe-se que a formação de competência nos docentes terá sucesso se as diferentes formas e habilidade dos conteúdos forem lecionadas, de forma 
complementar, pois desta forma os aprendizes toma-se aptos a relacionar os conhecimentos científicos ao uso social de saberes. Para que assim seja possível atingir os objetivos de ensino de geografia. Diante disso, o objetivo da geografia escolar é formar cidadãos para pensar o espaço geográfico e nele atuar de modo a desenvolver a sua cidadania pois "a aprendizagem escolar orienta e estimula processos internos de desenvolvimento" Vygotsky (VYGOTSKY, LURIA e LEONTIEV, 2001, p.116) .

Nesse caso, é preciso determinar os objetivos da educação, para definir o que ensinar, pois a escola, lugar de socialização do saber e hoje deve desenvolver capacidades além da cognitiva é fundamental que haja um equilíbrio dos diferentes tipos de conteúdo.

O ensino de geografia no ambiente escolar, assim como de outras disciplinas, em decorrência de ser apresentado de caráter essencialmente conceitual, teórico e abstrato é um grande desafio de romper a cultura da aprendizagem em sala de aula que se consolida o formato escolar frequentemente predominante, que se mantêm conteudista diante das realidades postas. Insuficiente de tempo para cumprir todos os tópicos curriculares, quantidade excessiva e diversidade de alunos em sala de aula, dificuldades em encontrar desafios adequados para a necessidades da aprendizagem de avaliações somativas são algumas barreiras encontradas para a efetivação de um ensino que privilegio o desenvolvimento das competências mencionadas.

Ao analisar propostas curriculares no ensino da geografia é possível identificar algumas indefinições na escolha de seus conteúdos onde há uma preocupação maior com os conteúdos conceituais ficando restrita, a conteúdo subjetivo e efetivo da relação da sociedade com a natureza que não prioriza a luta de classes, assim a aprendizagem de fenômenos e conceitos muitas vezes desconsiderando a aprendizagem de procedimentos e atitudes fundamentais para a compreensão dos métodos e explicação com os quais a própria geografia trabalha.

A proposta do PCN para a Geografia do ensino médio é tornar o sujeito processo de ensino aprendizagem em âmbito local, regional nacional e global a, é fornecer ao estudante condições para construir competência que permitam a análise do cotidiano, mostrando suas causas e efeitos intensidade, 
heterogeneidade e o contexto espacial que configuram cada sociedade. $O$ ensino médio deve servir para a ampliação das possibilidades de um conhecimento mediado pela unidade de ensino onde a escola conduza á autonomia necessária para cada indivíduo.

Para que isto se concretize o PCN orienta que sejam seguidos três princípios filosóficos da concepção curricular: princípios estéticos, político e éticos; a geografia contribui nesta formação proporciona ao estudante orientações ligada ao espaço, reconhecendo não somente sociedadenatureza, mas as inter-relações existentes; reconhecendo as contradições e conflitos econômicos, sociais e culturais avaliando a qualidade de vida a identidade do cidadão e esclarecendo da sua responsabilidade através da sua identidade cultural (BRASIL, 1996).

Deste modo é imprescindível ir além dos limites conceituais, buscando interdisciplinaridade com outras ciências, sem perder sua analogia. Sendo assim a Geografia dialoga com as demais ciências e aliando conhecimento quando necessário.

Faz-se necessário ir além dos limites conceituais, buscando interatividade com outras ciências, sem perder sua identidade. Sendo assim, o ideal é que a geografia articule de forma interdisciplinar com as demais ciências e incorporando conhecimentos quando necessário.

\section{As Mídias no Cotidiano dos Docentes do Ensino Médio}

Nos dias atuais, permeada pelo avanço vertiginoso da tecnologia, a figura do docente tradicional, não encontra mais lugar na escola. Esse docente tem anseios e necessita adaptar-se aos progressos de um tempo que não volta atrás. Sobre os nativos e imigrantes digitais Prensky, (2001) relata que os estudantes, nativos digitais, são ensinados por professores imigrantes, o qual advém de uma cultura pré-internet (TORI, 2010 p.18)

Diante disso, surgem várias proposições para as novas funções da escola, do educador e, consequentemente, também do educando. Ou seja, apresentam-se novas propostas que devem ser incorporadas ao sistema educativo para que todos estejam direcionados, visando a melhorias no

processo de ensino-aprendizagem. É imprescindível que o docente se desvincule dos métodos tradicionais, arraigados a suas entranhas para exercer 
essa função na sociedade contemporânea. A utilização de recursos tecnológicos como ferramenta de aprendizagem vem aumentando de forma muita acelerada e, os professores que têm um papel fundamental no processo educativo precisam reconhecer que:

\begin{abstract}
Novas exigências educacionais pedem às universidades e cursos de formação para o magistério um professor capaz de ajustar sua didática às novas realidades da sociedade, do conhecimento, do aluno, dos diversos universos culturais, dos meios de comunicação. O novo professor precisaria, no mínimo, de uma cultura geral mais ampliada, capacidade de aprender a aprender, competência para saber agir na sala de aula, habilidades comunicativas, domínio da linguagem informacional, saber usar meios de comunicação e articular as aulas com as mídias e multimídias (LIBÂNEO, 1998, p.4).
\end{abstract}

Para que esses novos desafios sejam alcançados, o docente necessita realizar a sua prática de ensino voltada ao processo de ensino aprendizagem dos alunos com a máxima eficácia, além de dominar os saberes necessários a seu exercício docente, adequar-se e estar capacitado para a utilização desses recursos tecnológicos voltados aos fins educacionais. Esses recursos da tecnologia educacional referem-se a:

Uma inovação pedagógica fundamentada no construtivismo sócio interacionista que, com os recursos da informática, levará o educador a ter muito mais oportunidade de compreender os processos mentais, os conceitos e as estratégias utilizadas pelo aluno e, com esse conhecimento, mediar e contribuir de maneira mais efetiva nesse processo de construção do conhecimento (FARIA, 2004, p.57).

Adaptar-se ao emprego dessas inovações é uma necessidade básica já que, o crescimento vertiginoso do uso tecnológico no ultimo anos, vem crescendo e os educadores não têm como se esquivar. Vale destacar que para aplicar esses recursos tecnológicos os professores precisam rever algumas questões como insegurança, falta de habilidade com o uso de tecnologia, despreparo para adequar o planejamento dos conteúdos a tecnologia digital, etc. Para resolver esses problemas é necessário que:

Os professores estejam sempre se aperfeiçoando para interagir com essa geração 'moderna' e 'mais informada'. Portanto, é importante que haja um investimento maior na formação de professores para o uso destes recursos, pois, as formações acontecem através de cursos ou treinamentos, com isso, o professor não analisa os obstáculos e as potencialidades. É fundamental formar continuamente esse novo professor que vai atuar nesse ambiente telemático, onde a tecnologia será um recurso mediado por ele para ampliar as possibilidades de aprendizagem no espaço escolar (LIMA, 2013, p. 103). 
Nesse intuito a aplicação das tecnologias, por parte dos professores, depende de uma mediação pedagógica, pois não se pode apenas utilizar os recursos tecnológico, sem um projeto alinhado aos conteúdos em prol da aprendizagem. É necessário que o docente se organize, se programe através de um planejamento em que os recursos tecnológicos o auxilie de forma dinâmica no processo educacional.

\section{A Formação Continuada das TICS Para os Professores de Geografia}

A prática pedagógica no atual senário mundial solicita do docente uma prática reflexiva e criativa relacionada ao domínio de conteúdo, aquisição de habilidades e diversificação de estratégias relacionadas ao conteúdo. Esses são fatores fundamentais ao processo de ensino aprendizagem, que por consequência exigem do docente uma postura diferenciada.

Ensinar e aprender requer hoje que o professor em sua prática pedagógica, além da lousa e piloto inclua em sua metodologia informações diversas e fontes variadas que construa e aplique conhecimento à realidade, pois:

Nos saberes necessários à educação do futuro o ensino da geografia com o auxílio das TICs solicita novas competências e habilidade do professor para o processo de ensino e aprendizagem que exigem mudanças em suas práticas docentes (MORIM, 2001, p. 28).

Adotando estas novas concepções do uso das tecnológicas no ensino da geografia, o conhecimento passa a ser construído e não mais imposto. E a escola nesse contexto estará exercendo sua função, formando pessoas mais criativas, críticas, autônomas, motivadas e felizes. Entretanto, para que realmente este seja um processo eficaz, o educador deve estar atento ao caminho percorrido e ao planejamento das estratégias de ação.

A aula de geografia do ensino médio deve ser elaborada visando ensinar e aprender explorando os diversos meios para o processo de aprendizagem bem como a utilização dos multimeios de forma planejada, como suportes complementares à prática pedagógica, e nos dias atuais:

Ensinar e aprender exige hoje muito mais flexibilidade, pessoal e de grupo menos conteúdo fixos e processos mais abertos à pesquisa $\mathrm{e}$ de comunicação. Antes a sala de aula era exclusivamente para desenvolvê-lo o trabalho docente, hoje há outra realidade com os avanços tecnológicos. Pois há necessidade de variar estratégias para 
motivar a aprendizagem como para responder aos diferentes formas e ritmos de aprendizagem (MORAM, 2006, p. 29).

Nesse contexto é necessário haver cursos de formação continuada destinada aos professores - neste caso particular de geografia - que estão atuando, uma vez que esses docentes influentes em sala de aula não tiveram em seus cursos de licenciatura preparação para o uso da Tecnologia da Informação (TIC) atrelado ao seu processo aprendizagem. Nesta perspectiva a educação torna-se mais do que nunca, um dos pilares essenciais para o desenvolvimento das novas habilidades exigidas pela sociedade digital. Vale salientar que:

\begin{abstract}
A profissão de professor combina sistematicamente elementos teóricos com situações práticas reais. É difícil pensar na possibilidade de educar fora de uma situação concreta e de uma realidade definida. Por essa razão, a ênfase na prática como atividade formativa é um dos aspectos centrais a ser considerado, com consequências decisivas para a formação profissional (LIBÂNEO, 2004, p.230).
\end{abstract}

O professor não é mais dono do conhecimento e sim mediador do saber, onde a sociedade the exige um novo perfil profissional capaz de encarar 0 desafio de inserir de forma adequada ás novas tecnologias na escola. Ou seja, um profissional com uma nova prática que permite a cada educando explorar ao máximo suas potencialidades, proporcionando um ambiente capaz de fornecer conexões individuais e coletivas.

Nesta perspectiva o professor torna-se mais do que nunca, um dos pilares essenciais para o desenvolvimento das novas habilidades exigidas pela sociedade digital.

\title{
Considerações Finais
}

O ensino da Geografia deve levar o aluno a compreender de forma ampla a realidade, possibilitando que nela interfiram de maneira mais consciente. Para tanto é preciso que adquira conhecimentos, dominem categorias, conceitos e procedimentos básicos com os quais este campo de conhecimento opera e constitui suas teorias de modo que possam compreender as relações socioeconômicas e o funcionamento da natureza ás quais a pertence e pensar sobre sua realidade.

As concepções pedagógicas renovadas é uma metodologia onde o aprendiz é visto como um ser autônomo, operante e apto a conquistar o saber. 
O professor é o condutor desse processo enquanto o meio ambiente atua como a necessária motivação dos alunos para seguir na direção do conhecimento e sugerem participações do aluno no processo de aprendizagem, assim as aulas estruturadas com base no diálogo entre o professor e alunos possibilitando protagonismo, liberado e autonomia dos sujeitos.

Ensinar e aprender no contexto de sala de aula requer a interligação do pensamento dos sujeitos na interação manifestada, valorizando o papel da comunicação e do discurso, visando alcançar a eficácia na compreensão dos científicos estudados de formas compartilhadas. A linguagem não pode ser considerada apenas como instrumento de comunicação, uma vez que ela é pode ser empregada para a compreensão do pensamento conceitual, ou seja, a linguagem é uma ferramenta utilizada pelo professor para melhorar a aula expositiva de geografia

A aprendizagem é entendida como ação transformadora e que os alunos participem de maneira significativa, interagindo com as explicações do docente a fim que possa desenvolver reflexões sobre temas estudados na aula. 0 processo de ensino e aprendizagem não é algo simples, ele engloba diversas medidas que devem ser tomadas para que a aprendizagem aconteça realmente.

\section{Referências}

BRASIL. Lei de Diretrizes e Bases da Educação Nacional, LDB. 9394/1996. Brasília: MEC/SEF, 1996

BRASIL. Parâmetros Curriculares Nacionais (PCNs). Introdução. Ensino. Fundamental. Brasília: MEC/SEF, 1998

FARIA, E. T. O Professor e as Novas Tecnologias. Porto Alegre: Dissertação, 2004

LIBÂNEO, J. C. Educação e profissão docente. São Paulo: Cortez, 1998.

LIBÂNEO, J. C. Organização e gestão da escola: teoria e prática. 5.ed. revista e ampliada. Goiânia: Editora Alternativa, 2004.

LIMA, M. F. Formação dos professores para a inserção das mídias em sala de aula: uma proposta de ação, reflexão e transformação.[s.l.] HOLOS, 2013

MORAN, J. M. Novas tecnológicas e mediação pedagógica. Campinas, SP: Papirus, 2006 
PRENSKY, M. Nativos Digitais, Imigrantes Digitais. 2001 Obtido em http://www.marcprensky.com/ escrita / prensky\% 20\% 20digital\% 20natives,\% 20digital\% 20 imigrantes\% 20-\% 20part1.pdf

TORI, R. Educação sem distância: as tecnologias interativas na redução de distância em ensino e aprendizagem. São Paulo: Editora Senac, 2010.

VYGOTSKY, L. LURIA; LEONTIEV, A. Linguagem, desenvolvimento e aprendizagem. São Paulo: Ícone. 2001. 